\title{
Role of vanadium and pyridine in heteropolycompounds for selective oxidation of alcohols with hydrogen peroxide
}

\author{
VALERIA PALERMO ${ }^{\mathrm{a}}$, PAULA I VILLABRILLE ${ }^{\mathrm{a}, \mathrm{b}}$, PATRICIA G VÁZQUEZ ${ }^{\mathrm{a}}$, \\ CARMEN V CÁCERES ${ }^{\mathrm{a}}$, PIETRO TUNDO ${ }^{c}$ and GUSTAVO P ROMANELLI ${ }^{\mathrm{a}, \mathrm{b}, *}$ \\ aCentro de Investigación y Desarrollo en Ciencias Aplicadas “Dr. Jorge J. Ronco" (CINDECA), \\ Departamento de Química, Facultad de Ciencias Exactas, Universidad Nacional de La Plata-CCT-CONICET. \\ Calle 47 Nro 257, B1900AJK La Plata, Argentina \\ ${ }^{b}$ Facultad de Ciencias Agrarias y Forestales, Universidad Nacional de La Plata. Calles 60 y 119 s/n, \\ B1904AAN La Plata, Argentina \\ ${ }^{c}$ Department of Environmental Science, Cà Foscari University, Dorsoduro 2137, 30123 Venice, Italy \\ e-mail: gpr@quimica.unlp.edu.ar
}

MS received 22 April 2013; revised 27 August 2013; accepted 30 August 2013

\begin{abstract}
This study describes the application of heteropolyacids $\mathrm{H}_{3} \mathrm{PMo}_{12} \mathrm{O}_{40}, \mathrm{H}_{4} \mathrm{SiMo}_{12} \mathrm{O}_{40}$, $\mathrm{H}_{4} \mathrm{PMo}_{11} \mathrm{VO}_{40}, \mathrm{H}_{5} \mathrm{PMo}_{10} \mathrm{~V}_{2} \mathrm{O}_{40}, \mathrm{H}_{9} \mathrm{PMo}_{6} \mathrm{~V}_{6} \mathrm{O}_{40}$, and a hybrid pyridine-modified heteropolyacid with Keggin structure for selective oxidation of alcohols to ketones or aldehydes using aqueous hydrogen peroxide and acetonitrile as solvent. Performance of these different catalysts in 1-phenylethanol oxidation was studied. Influence of reaction temperature, amount of catalyst and hydrogen peroxide and reaction time on the yield of acetophenone was investigated to obtain optimal reaction conditions. Oxidation ability of the catalyst depended on the number of vanadium atoms present in the Keggin ion and to a lesser extent on pyridine substitution in the Keggin secondary structure. In order to explore the applicability of the method for selective oxidation of alcohols to ketones or aldehydes, various alcohols were investigated according to the general procedure using hybrid pyridine-modified heteropolyacid.
\end{abstract}

Keywords. Oxidation reaction; alcohol oxidation; vanadium-substituted heteropolyacids; pyridinium heteropolyacid salt.

\section{Introduction}

Selective oxidation of organic substrates is an important transformation in organic synthesis and several methods are known for this particular conversion. ${ }^{1}$ Aldehydes and ketones are essential intermediates for many drugs, vitamins, fragrances and food additives, and as intermediates in organic syntheses such as Aldol, Michael, Cannizaro and Perkins reactions. ${ }^{2}$

Several methods are reported in literature for the selective oxidation of alcohols and this transformation is of great significance to the synthetic organic community. ${ }^{1}$ Classical methodologies for this transformation use conventional mineral oxidants in stoichiometric amounts. ${ }^{3,4}$

The described method generates considerable amount of inorganic waste and is not environmentally attractive. Consequently, one of the preferred solutions is to use hydrogen peroxide as an oxygen donor in

*For correspondence catalytic oxygen transfer reactions. The use of aqueous hydrogen peroxide as an oxidant is very attractive, since it is environmentally friendly and easy to handle. ${ }^{5}$ A variety of different catalytic systems for the hydrogen peroxide-promoted oxidation of alcohols have been developed, e.g., tungsten-based polyoxometalate catalyst, ${ }^{6,7}$ Lewis acid iron aluminum chloride, ${ }^{8}$ dinuclear Mn (IV) complexes, ${ }^{9}$ metal-organic gel-based on $\mathrm{Fe}(\mathrm{III})^{10}$ and $\mathrm{CuCl}_{2}$ bifunctional ionic liquid. ${ }^{11}$ Recently, Maity et al. described an efficient aqueous system to perform selective oxidation of primary and secondary alcohols using platinum nanoparticules as catalyst. ${ }^{12}$

On the other hand, the design of a new catalyst which gives excellent conversion with maximum selectivity for organic transformation is one of the challenges in the field of catalysis. In well-known that materials based on vanadium are excellent catalysts in different oxidation procedures. Among the various transition metals, vanadium, an early member of the $3 \mathrm{~d}$ transition metal series, exists on the surface of the earth more abundantly and vanadium-base oxidant are effectively used 
for various oxidation reactions such as methanol oxidation, carbon monoxide oxidation, partial oxidation of hydrocarbons and many organic transformations. ${ }^{13}$ For example, a recent report by Gopinath and co-workers describes the use of nanocrystalline $\mathrm{Ti}_{1 . \mathrm{X}} \mathrm{V}_{\mathrm{X}} \mathrm{O}_{2}$ as efficient catalyst in the oxidative dehydrogenation of ethyl benzene, using oxygen as friendly oxidant. ${ }^{14}$

Heteropolyacids (HPAs) are transition metal-oxygen anion clusters that exhibit a wide range of molecular sizes, compositions and architectures. ${ }^{15}$ There is an increasing interest in the area of heteropolycompoundinduced organic transformations. HPAs have been used in a variety of acid-catalysed reactions such as esterification, etherification, olefin hydration and dehydration of alcohols and are also attractive as catalysts for oxidation processes. ${ }^{16}$ Recently, we have applied the use of Keggin HPAs in a wide range of processes, i.e., preparation of heterocycles, ${ }^{17,18}$ protection/deprotection of organic functional groups ${ }^{19,20}$ and oxidation processes, as well as substituted phenol, alcohol and amine oxidation, and the selective oxidation of sulphides to sulphoxides and sulphones. ${ }^{21-24}$

Vanadium-incorporated molybdophosphoric acid catalysts show unique catalytic features for oxidations due to their bifunctional character, which arises because of the redox nature of vanadium and the oxidation/acidic character of molybdophosphoric acid catalysts by replacing Mo atoms with corresponding $\mathrm{V}$ atoms. ${ }^{25}$ Several researchers have investigated vanadium-incorporated molybdophosphoric acid catalysts by replacing 1, 2 and 3 molybdenum atoms with corresponding number of vanadium atoms. Acidic, redox and thermal stability properties of vanadium catalysts are influenced by the degree of vanadium substitution. ${ }^{25}$ In solutions, reduction potentials of heteropolyanions containing Mo and $\mathrm{V}$ are high as these ions are easily reduced. Oxidative ability decreases generally in the order: V- > Mo- > W-containing heteropolyanions, which means that vanadium-containing heteropoly compounds are the strongest oxidants. ${ }^{26}$

As reported by Song et al., ${ }^{15}$ metal substitution may occur by modifying the energy and composition of the lowest unoccupied molecular orbital (LUMO) and consequently its redox properties. Substitution of vanadium ions in the molybdenum framework stabilizes the LUMOs because these orbitals derive in part from vanadium d-orbitals, which have been assumed to be more stable than those of molybdenum and tungsten.

These heteropolycompounds have recently been studied due to their importance in catalytic oxidation reactions, for example, hydroxylation of benzene, oxidation of toluene, nitrobenzene and norbornene using aqueous hydrogen peroxide, ${ }^{27}$ benzyl alcohol

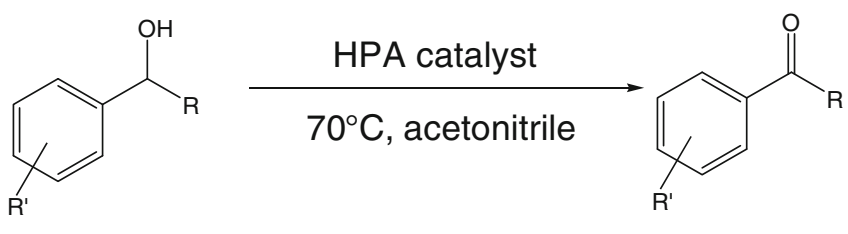

Scheme 1. Catalytic oxidation of benzylic alcohols in liquid phase.

oxidation, ${ }^{25}$ oxidation of benzoins to benzyls, aldehydes and esters by dioxygen, ${ }^{28}$ and liquid-phase oxidation of methane with hydrogen peroxide. ${ }^{29}$ Recently, Leng and co-workers ${ }^{30}$ reported the use of a pyridinemodified molybdovanadophosphate hybrid catalyst for direct hydroxylation of benzene by hydrogen peroxide in acetic acid and acetonitrile mixed solvent. They demonstrated that substituted vanadium atoms in HPAs are essentially active sites with high performance for hydroxylation of benzene to phenol.

In this study, vanadium-substituted HPAs were prepared. The $\mathrm{H}_{4} \mathrm{PMo}_{11} \mathrm{VO}_{40}$ was transferred to pyridinium salt to get the hybrid material $\mathrm{HPyH}_{3} \mathrm{PMo}_{11} \mathrm{VO}_{40}$. Then, we used these catalysts for the liquid-phase selective oxidation of alcohols with $35 \%$ (w/v) aqueous hydrogen peroxide $\left(\mathrm{H}_{2} \mathrm{O}_{2}\right)$ in acetonitrile as solvent at $70^{\circ} \mathrm{C}$ (scheme 1).

\section{Experimental}

\subsection{Catalytic preparation}

Commercially available $\mathrm{H}_{3} \mathrm{PMo}_{12} \mathrm{O}_{40}\left(\mathrm{PMo}_{12}\right)$ and $\mathrm{H}_{4} \mathrm{SiM}_{12} \mathrm{O}_{40}\left(\mathrm{SiMo}_{12}\right)$ were purchased from Aldrich. HPAs containing vanadium in the Keggin primary structure $\left[\mathrm{H}_{4} \mathrm{PMo}_{11} \mathrm{VO}_{40}\left(\mathrm{PMo}_{11} \mathrm{~V}\right), \mathrm{H}_{5} \mathrm{PMo}_{10} \mathrm{~V}_{2} \mathrm{O}_{40}\right.$ $\left(\mathrm{PMo}_{10} \mathrm{~V}_{2}\right)$ and $\left.\mathrm{H}_{9} \mathrm{PMo}_{6} \mathrm{~V}_{6}\left(\mathrm{PMo}_{6} \mathrm{~V}_{6}\right)\right]$ were prepared and fully characterized according to the procedure already published in the literature. ${ }^{26}$ Then, starting from $\mathrm{PMo}_{11} \mathrm{~V}$, a pyridinium salt, $\mathrm{HPyH} \mathrm{PMo}_{11} \mathrm{VO}_{40}$ $\left(\mathrm{Py}-\mathrm{PMo}_{11} \mathrm{~V}\right)$, was obtained. An ethanolic solution of aniline was added to an ethanolic solution of $\mathrm{PMo}_{11} \mathrm{~V}$. The mixture was stirred at $80^{\circ} \mathrm{C}$ for $1.5 \mathrm{~h}$. The precipitate was filtered, washed with ethanol and dried at $20^{\circ} \mathrm{C}$ in vacuum. The resulting fine orange powder was then dissolved in water to recrystallize for further purification.

\subsection{Catalytic characterization}

2.2a Fourier transform infrared spectroscopy: Thermo Bruker IFS 66 IR equipment was used to obtain the Fourier transform-Infrared (FT-IR) spectra of the solid samples. Samples were run in transmission mode with 
a wavenumber resolution of $4 \mathrm{~cm}^{-1}$. The solids were ground and mixed with BrK, previously dried in a stove, and pellets were formed. The measuring range was $400-4000 \mathrm{~cm}^{-1}$. Measurements were made in air and the effect of adsorbed moisture or carbon dioxide was eliminated using air as reference in the measurements.

2.2b Potentiometric titration: An amount of $0.05 \mathrm{~mL}$ of $0.1 \mathrm{~N} n$-butylamine (Carlo Erba) in acetonitrile (JT Baker) was added to a mass of solid $(0.05 \mathrm{~g})$ using acetonitrile as solvent, and stirred for $3 \mathrm{~h}$. Later, the suspension was titrated with the base solution at $0.05 \mathrm{~mL} / \mathrm{min}$. Electrode potential variation was measured with an Instrumentalia SRL digital $\mathrm{pH}$ meter, using a double junction electrode. This technique enables the evaluation of the total number of acid sites and their acid strength. In order to interpret the results, it is suggested that the initial electrode potential $(E)$ indicates the maximum acid strength of the surface sites, and the values (meq/g solid) where the plateau is reached indicates the total number of acid sites. Acid strength of surface sites can be assigned according to the following ranges: very strong site, $E>100 \mathrm{mV}$; strong site, $0<E<100 \mathrm{mV}$; weak site, $-100<$ $E<0 \mathrm{mV}$ and very weak site, $E<-100 \mathrm{mV}^{31}$

\subsection{Catalytic test}

2.3a 1-Phenylethanol oxidation: In all the reactions, a $25 \mathrm{~mL}$ three-necked round-bottomed flask heated at the reaction temperature and connected with a waterjacketed condenser, was used. The reactor was loaded with a mixture of $0.7 \mathrm{mmol}$ of 1-phenylethanol (Aldrich), $5 \mathrm{~mL}$ of acetonitrile, $1 \mathrm{~mL}$ of aqueous hydrogen peroxide $35 \%$ (w/v) (Analquim), $n$-dodecane (SigmaAldrich) as internal standard $(0.056 \mathrm{~g}, 0.39 \mathrm{mmol})$ and $1 \%$ mmol of the HPAs with respect to the substrate. The mixture was stirred at $700 \mathrm{rpm}$.

Samples were withdrawn from the organic phase at different intervals $(15,30,60,90$ and $120 \mathrm{~min})$. Each sample volume was approximately $20 \mu \mathrm{L}$ and was diluted with $2 \mathrm{~mL}$ of acetonitrile. Concentrations of substrates were calculated with an internal standard method, using a Varian gas chromatography 3400 instrument (Chromopack CP Sil 8 CB, $30 \mathrm{~m} \times 0.32 \mathrm{~mm}$ ID). Identification of products was performed with gas chromatography-mass spectrometry (GC-MS) (detector HP 5971).

2.3b General procedure for alcohol oxidation: Alcohols were purchased from Aldrich. Alcohol oxidations were performed under vigorous stirring in a glass reactor at $70^{\circ} \mathrm{C}$. Reactions were performed by adding $\mathrm{H}_{2} \mathrm{O}_{2} 35 \%(\mathrm{w} / \mathrm{v}$ ) in excess to a solution of $0.7 \mathrm{mmol}$ of the corresponding alcohols and the catalyst $(1 \% \mathrm{mmol})$ in acetonitrile $(5 \mathrm{~mL})$. The reaction was followed by thin-layer chromatography (TLC). The reaction mixture was diluted with $20 \mathrm{~mL}$ of distilled water and extracted twice with $10 \mathrm{~mL}$ of dichloromethane (JT Baker). Extract was dried over anhydrous sodium sulphate. Crude product was purified by column chromatography on silica gel using a mixture of hexane-toluene (1:1) (Cicarelli) as eluent. Products were identified by comparison of the mass spectra of standard samples. Selectivity of reaction was calculated as the molar ratio between the obtained amount of ketone or aldehyde and the total amount of the corresponding alcohols.

2.3c Quadrupole mass spectra of synthesized compounds: Acetophenone: $\mathrm{m} / \mathrm{z}(\%) 120$ (32), 105 (100), 77 (87), 51 (38), 43 (18); 4-Methylacetophenone: $\mathrm{m} / \mathrm{z}$ (\%) 134 (32), 119 (100), 91 (83), 55 (28), 43 (10), 39 (11); 4-Methoxyacetophenone: $m / z$ (\%) 150 (38), 135 (100), 107 (12), 92 (14), 77 (25), 43 (10); 4 Chloroacetophenone: $\mathrm{m} / z$ (\%) 156 (8), 154 (27), 141 (33), 139 (100), 113 (14), 111 (42), 75 (17), 50 (9), 43 (10); Benzophenone: $m / z$ (\%) 182 (42), 105 (100), 77 (60), 51 (23); 4,4'-Dimethylbenzophenone: $\mathrm{m} / z$ (\%) 210 (33), 195 (17), 119 (100), 91 (43), 76 (28), 39 (10); 4,4'-Dichlorobenzophenone: $m / z$ (\%) 254 (4), 253 (3), 252 (23), 251 (5), 250 (40), 215 (10), 131 (33), 129 (100), 75 (22), 50 (6); Benzaldehyde: $\mathrm{m} / \mathrm{z}$ (\%) 106 (92), 105 (89), 77 (100), 51 (50), 50 (28); 4Chlorobenzaldehyde: $\mathrm{m} / z$ (\%) 142 (23), 141 (42), 140 (71), 139 (100); 2-Octanone: $m / z$ (\%) 128 (6), 113 (4), 85 (7), 71 (19), 58 (86), 43 (100), 29 87); 2-Decanone: $\mathrm{m} / z$ (\%) 156 (5), 141 (2), 127 (2), 113 (2), 98 (5), 96 (5), 85 (5), 71 (38), 58 (100), 43 (85), 41 (27); Decanal: $\mathrm{m} / \mathrm{z}$ (\%) 156 (1), 138 (2), 128 (84), 112 (21), 96 (15), 95 (18), 84 (16), 83 (28), 82 (34), 81 (23), 71 (33), 70 (47), 69 (29), 68 (27), 67 (25), 57 (62), 56 (43), 55 (62), 44 (54), 43 (100), 41 (80), 29 (50), 27 (33).

\section{Results and discussion}

\subsection{Catalysis characterization}

Vibration spectra of bulk heteropolyacids with Keggin structure are modified as a function of the nature of the elements introduced in their structure. The main changes observed when $\mathrm{Mo}^{+6}$ atoms are substituted by $\mathrm{V}^{+5}$ atoms in the structure of $\mathrm{PMo}_{12}$ are a frequency decrease of the $\mathrm{Mo}=\mathrm{O}_{\mathrm{d}}$ band, and a possible splitting of the $\mathrm{P}-\mathrm{O}_{\mathrm{a}}$ band. ${ }^{26}$ In the FT-IR spectrum of $\mathrm{PMo}_{11} \mathrm{~V}$ 
(figure 1), bands at 1062 and $1081\left(\mathrm{P}-\mathrm{O}_{\mathrm{a}}\right), 960$ $\left(\mathrm{Mo}=\mathrm{O}_{\mathrm{d}}\right), 866\left(\mathrm{Mo}-\mathrm{O}_{\mathrm{b}}-\mathrm{Mo}\right)$, and $776\left(\mathrm{Mo}-\mathrm{O}_{\mathrm{c}}-\mathrm{Mo}\right)$ $\mathrm{cm}^{-1}$ were observed. These values, compared with those corresponding to $\mathrm{PMo}_{12}$, agree with the indicated behaviour. Similar changes can be seen for vibrational spectra of $\mathrm{PMo}_{10} \mathrm{~V}_{2}$ and $\mathrm{PMo}_{6} \mathrm{~V}_{6}$. This indicates that indeed $\mathrm{V}$ has been incorporated into the Keggin units.

The FT-IR spectra of pyridinium salt $\left(\mathrm{Py}-\mathrm{PMo}_{11} \mathrm{~V}\right)$ showed the four peaks assigned to the Keggin-structure heteropolyacid $\left(\mathrm{PMo}_{11} \mathrm{~V}\right)$ and a characteristic band for pyridinium ion at $1483 \mathrm{~cm}^{-1}$, in good agreement with a previous report. ${ }^{30}$ This behaviour indicates that pyridine acts as countercation and does not modify the Keggin units.

Potentiometric titration with $n$-butylamine of the synthesized HPAs was carried out. According to these results, a relative order of maximum acid strength can be assigned as follows: $\mathrm{Py}_{-} \mathrm{PMo}_{11} \mathrm{~V}>\mathrm{PMo}_{11} \mathrm{~V}>$ $\mathrm{PMo}_{12} \gg \mathrm{PMo}_{10} \mathrm{~V}_{2}>\mathrm{PMo}_{6} \mathrm{~V}_{6} \cdot \mathrm{PMo}_{11} \mathrm{~V}$ shows very strong sites, with a maximum acid strength, corresponding to an initial electrode potential of $978 \mathrm{mV}$, which is higher than that obtained for the V-free sample, $600 \mathrm{mV}$ (figure 2). When $\mathrm{PMo}_{11} \mathrm{~V}$ was transformed into hybrid material $\left(\mathrm{Py}-\mathrm{PMo}_{11} \mathrm{~V}\right)$, acid strength increased from 978 to $1100 \mathrm{mV}$, and potentiometric titration curve was very similar to that of the corresponding HPA. In the case of $\mathrm{PMo}_{10} \mathrm{~V}_{2}$ and $\mathrm{PMo}_{6} \mathrm{~V}_{6}$ acids, acid strength decreased. When the number of $\mathrm{V}$ atoms increases,

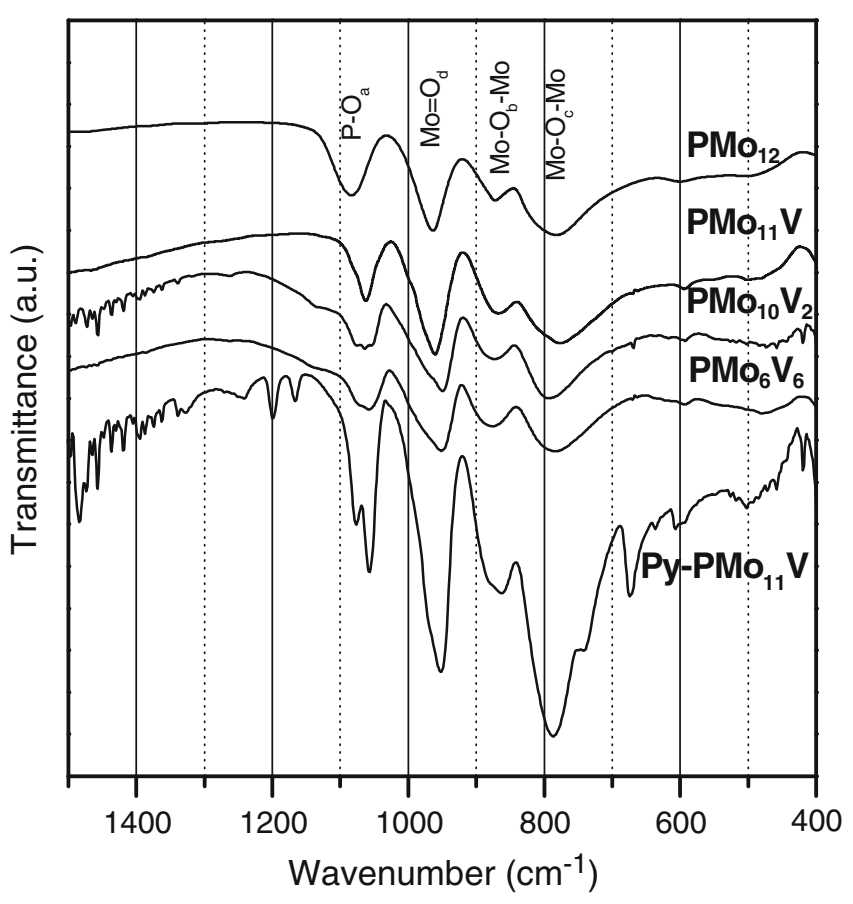

Figure 1. FT-IR spectra of $\mathrm{PMo}_{12}, \mathrm{PMo}_{11} \mathrm{~V}, \mathrm{PMo}_{10} \mathrm{~V}_{2}$, $\mathrm{PMo}_{6} \mathrm{~V}_{6}$ and $\mathrm{Py}-\mathrm{PMo}_{11} \mathrm{~V}$ samples.

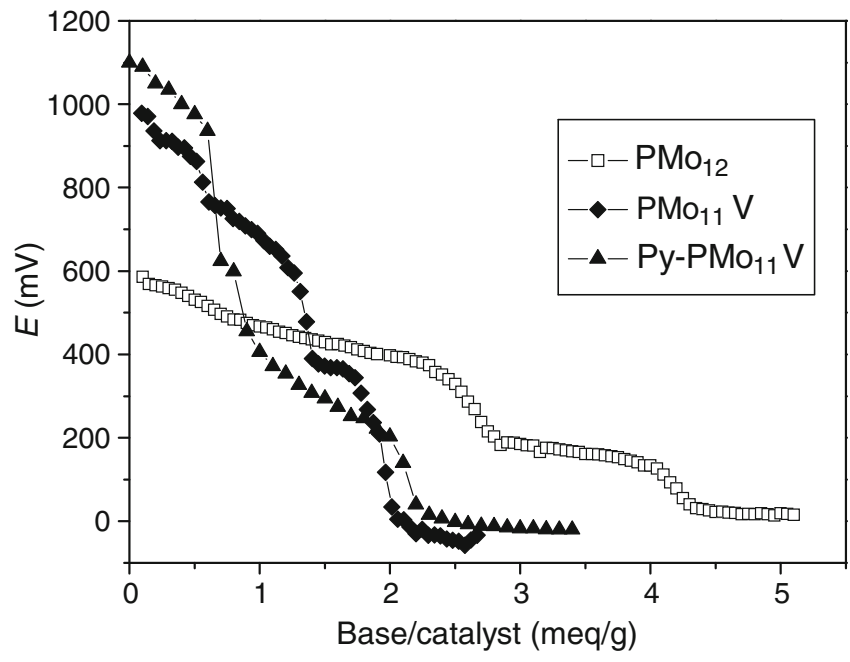

Figure 2. Potentiometric titration curves for $\mathrm{PMo}_{12}$, $\mathrm{PMo}_{11} \mathrm{~V}$ and $\mathrm{Py}-\mathrm{PMo}_{11} \mathrm{~V}$.

charge of the anion is higher. Consequently, the anionproton interaction increases and acidity of the compounds decreases.

\subsection{Catalytic performance}

This study describes the application of a homogeneous system for the oxidation of alcohols to ketones or aldehydes with aqueous hydrogen peroxide in the presence of Keggin HPAs as catalyst. Influence of vanadium-doped atoms in the primary structure and pyridine in the secondary structure of different synthesized catalysts was also considered. Figure 3 shows the results obtained for 1-phenylethanol conversion using different catalysts. A high selectivity of benzophenone was obtained $(96-100 \%)$ with traces of a secondary product, 4-hydroxyacetophenone.

In all cases, the catalyst reaches certain conversion value in the first 30 min and no further changes occur afterwards. This is a consequence of the hydrogen peroxide decomposition. In a blank experiment, $1 \mathrm{~mL}$ of $35 \% \mathrm{p} / \mathrm{v}$ of hydrogen peroxide in $4 \mathrm{~mL}$ of acetonitrile, in the presence of catalyst $(1 \mathrm{mmol} \%)$, was stirred at $70^{\circ} \mathrm{C}$ for $30 \mathrm{~min}$. Titration of hydrogen peroxide remainder showed a $100 \%$ of hydrogen peroxide decomposition.

3.2a Effects of vanadium content in the heteropolyacid on catalytic oxidation of 1-phenylethanol: Table 1 shows the results of 1-phenylethanol oxidation to acetophenone with aqueous hydrogen peroxide using different catalysts. Blank experiment was performed in the absence of catalyst. Under these conditions, 


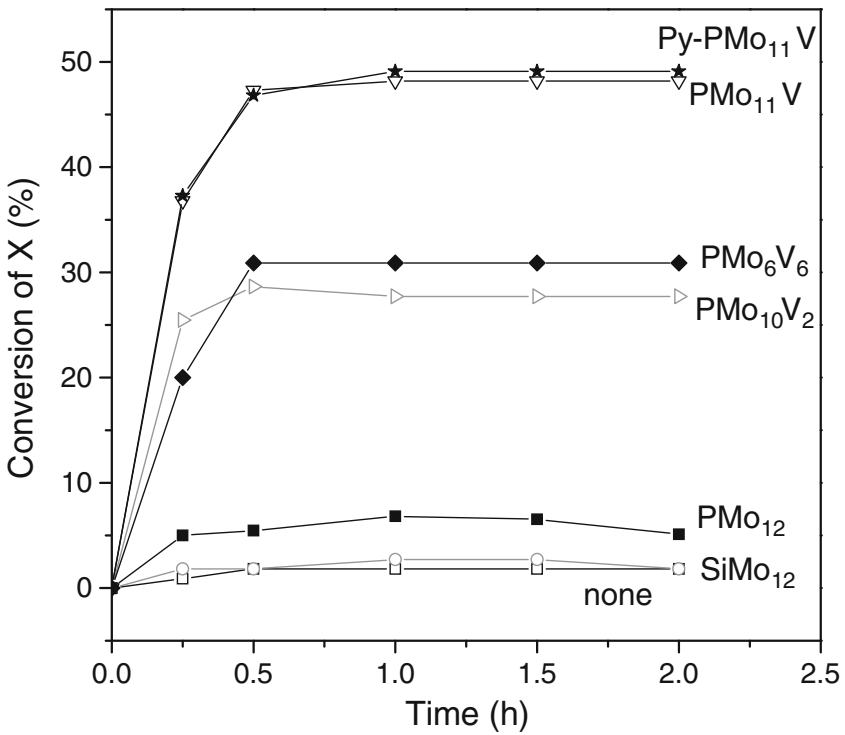

Figure 3. Effect of reaction time on conversion of 1phenylethanol (X) to acetophenone (Y) using different synthesized catalysts.

reaction conversion was very low $(2 \%$ in $2 \mathrm{~h})$ at $70^{\circ} \mathrm{C}$ (table 1, entry 1).

We performed oxidation reaction of 1-phenylethanol using two commercial Keggin HPAs $\left(\mathrm{PMo}_{12}\right.$ and $\mathrm{SiMo}_{12}$ ). Conversion was very low, $5 \%$ and $4 \%$ for $\mathrm{PMo}_{12}$ and $\mathrm{SiMo}_{12}$, respectively (table 1 , entries 2 and $3)$. Only a trace amount of acetophenone was observed.

Results of 1-phenylethanol oxidation using the prepared catalysts $\left(\mathrm{PMo}_{11} \mathrm{~V}, \mathrm{PMo}_{10} \mathrm{~V}_{2}\right.$ and $\left.\mathrm{PMo}_{6} \mathrm{~V}_{6}\right)$ are listed in table 1, entries 4-6. In these cases, higher yields of acetophenone were reached, indicating that the presence of vanadium atoms is essential for performing oxidation reaction. This is in accordance with previous reports. ${ }^{25,26,29}$ However, the conversion of 1-phenylethanol and the turnover number (TON) decreases with the content of substituted vanadium atoms in the HPA, i.e., catalytic activities of the three catalysts increased in the following order: $\mathrm{PMoV}_{2} \sim \mathrm{PMoV}_{6}<\mathrm{PMo}_{11} \mathrm{~V} . \mathrm{PMo}_{11} \mathrm{~V}$ showed the best performance (table 1, entry 4). A conversion of $48 \%$ was observed at $2 \mathrm{~h}$, with $97.9 \%$ of acetophenone selectivity. In this case, traces of a secondary product, 4-hydroxyacetophenone, were detected.

Improvement in the catalytic activity of vanadiumHPAs is in agreement with redox potential values reported in the literature, $0.52 \mathrm{~V}$ for $\mathrm{PMo}_{12}{ }^{33}$ and $0.65 \mathrm{~V}$ for $\mathrm{PMo}_{11} \mathrm{~V}^{26}$

Maximum acid strength also decreased when the number of $\mathrm{V}$ atoms in the HPAs increased. Therefore, it could be assumed that the higher yield of acetophenone from 1-phenylethanol resulted from two factors: the oxidative ability and acidic properties of HPA. Brønsted acidity is an important catalytic property since protons could be involved in the mechanism of oxidation reaction. ${ }^{34}$

On the other hand, a previous study reported that pyridine incorporation in the secondary structure of HPAs can increase catalytic activity. ${ }^{30}$ For this reason, we prepared a hybrid vanadium-substituted HPA catalyst $\left(\mathrm{Py}-\mathrm{PMo}_{11} \mathrm{~V}\right)$, which was tested in 1-phenylethanol oxidation under aforementioned conditions. A slight effect of pyridine on the yield of ketones or aldehydes was observed. A conversion of $49 \%$ was observed

Table 1. Catalytic performance of different HPAs in 1-phenylethanol oxidation.

\begin{tabular}{llccccc}
\hline Entry & Catalyst & 1-PHE conv. $^{\mathrm{a}}(\%)$ & APH yield $(\%)$ & APH select. $^{\mathrm{c}}(\%)$ & TON $^{\mathrm{d}}$ & TON-V $^{\mathrm{e}}$ \\
\hline 1 & None & 2 & 2 & 100 & 1.4 & - \\
2 & $\mathrm{PMo}_{12}$ & 5 & 5 & 100 & 3.5 & - \\
3 & $\mathrm{SiMo}_{12}$ & 4 & 4 & 100 & 2.8 & - \\
4 & $\mathrm{PMo}_{11} \mathrm{~V}$ & 48 & 47 & 97.9 & 32.9 & 32.9 \\
5 & $\mathrm{PMo}_{10} \mathrm{~V}_{2}$ & 28 & 27 & 96.4 & 18.9 & 9.45 \\
6 & $\mathrm{PMo}_{6} \mathrm{~V}_{6}$ & 32 & 31 & 96.8 & 21.7 & 3.61 \\
7 & $\mathrm{Py}^{-\mathrm{PMo}_{11} \mathrm{~V}}$ & 49 & 48 & 97.9 & 34.3 & 34.3 \\
\hline
\end{tabular}

Experimental conditions: $0.01 \mathrm{mmol}$ catalyst, $0.7 \mathrm{mmol}$ of 1-phenylethanol, $1 \mathrm{~mL}$ of $\mathrm{H}_{2} \mathrm{O}_{2} 35 \%$ (w/v) and $5 \mathrm{~mL}$ of acetonitrile; reaction for $2 \mathrm{~h}$ at $70^{\circ} \mathrm{C} .1-\mathrm{PHE}=1$ phenylethanol; $\mathrm{APH}=$ acetophenone; $4 \mathrm{OHAPH}=$ 4-hydroxyacetophenone (a secondary product)

${ }^{a}$ Conversion (\%) of 1-PHE calculated as mmol 1-PHE/mmol of initial 1 -PHE $\times 100$

b Yield (\%) of APH calculated as mmol APH/mmol of initial 1-PHE $\times 100$

${ }^{c}$ Selectivity $(\%)$ of APH calculated as $\mathrm{mmol} \mathrm{APH} /(\mathrm{mmol}$ of AHP + mmol 4OHAPH $)$

$\mathrm{d}$ Turnover number calculated as $\mathrm{mmol} \mathrm{APH} / \mathrm{mmol}$ catalyst

e Turnover number calculated as $\mathrm{mmol} \mathrm{APH} / \mathrm{mmol} \mathrm{V}$ atom in polyoxometalates ${ }^{32}$ 

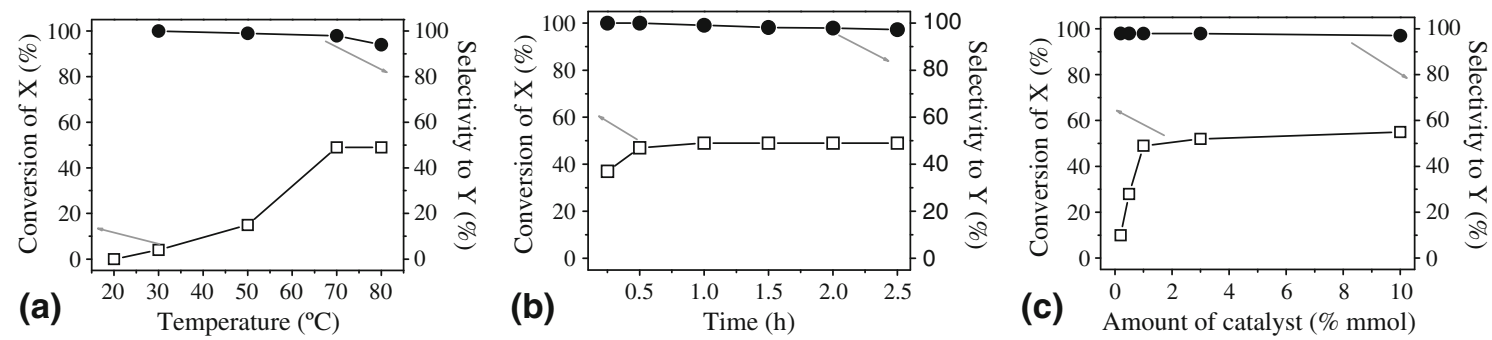

Figure 4. (a) Effect of reaction temperature on the conversion of 1-phenylethanol (X) and selectivity to acetophenone (Y) in 1-phenylethanol oxidation using Py- $\mathrm{PMo}_{11} \mathrm{~V}$; (b) effect of reaction time on conversion of 1-phenylethanol (X) and selectivity to acetophenone (Y) using Py-PMo ${ }_{11} \mathrm{~V}$ catalyst; (c) effect of amount of catalyst on conversion of 1-phenylethanol (X) and selectivity to acetophenone (Y) using $\mathrm{Py}-\mathrm{PMo}_{11} \mathrm{~V}$ catalyst.

at $2 \mathrm{~h}$, with $97.9 \%$ of acetophenone selectivity (table 1 , entry 7) compared to the $\mathrm{PMo}_{11} \mathrm{~V}(48 \%$ and $97.9 \%$, respectively, table 1 , entry 4 ).

Pyridine in the secondary structure of HPA can promote catalytic activities of the hybrid catalyst due to electronic interaction between pyridine and HPA along with the more remarkable pseudo-liquid-phase behaviour, as reported by Leng and co-workers. ${ }^{30}$

3.2b Effect of reaction temperature on catalytic oxidation of 1-phenylethanol: Influence of reaction temperature on reactivity of 1-phenylethanol oxidation was investigated using $\mathrm{Py}-\mathrm{PMo}_{11} \mathrm{~V}$, and the results are illustrated in figure $4 \mathrm{a}$. Five temperatures were tested $\left(20^{\circ}, 30^{\circ}, 50^{\circ}, 70^{\circ}\right.$ and $\left.80^{\circ} \mathrm{C}\right)$. No 1-phenylethanol conversion was observed at $20^{\circ} \mathrm{C}$. A higher temperature leads to a higher 1-phenylethanol conversion. This is only $15 \%$ at $50^{\circ} \mathrm{C}$, after $1 \mathrm{~h}$, whereas at $70^{\circ} \mathrm{C}$, conversion is $48 \%$, which is three times higher. An increase of only $1 \%$ is observed when the temperature is raised from $70^{\circ}$ to $80^{\circ} \mathrm{C}$.

As regards acetophenone selectivity, a slight decrease with temperature was observed $\left(97.9 \%\right.$ to $94 \%$, at $70^{\circ}$ and $80^{\circ} \mathrm{C}$, respectively). This could be due to further oxidation of acetophenone to 4-hydroxyacetophenone. For this reason, $70^{\circ} \mathrm{C}$ was employed as optimum temperature.

\section{2c Effect of reaction time on catalytic oxidation of} 1-phenylethanol: Figure $4 \mathrm{~b}$ shows the result for selective oxidation of 1-phenylethanol as a function of reaction time using $\mathrm{Py}-\mathrm{PMo}_{11} \mathrm{~V}$ catalyst at a reaction temperature of $70^{\circ} \mathrm{C}$. It can be observed that conversion of 1-phenylethanol increases with reaction time up to $0.5 \mathrm{~h}$ and then it does not change. Selectivity of acetophenone decreases slightly with reaction time.

3.2d Effect of amount of Py-PMo ${ }_{11} V$ on catalytic oxidation of 1-phenylethanol: Figure 4c displays the effect of amount of $\mathrm{Py}-\mathrm{PMo}_{11} \mathrm{~V}$ on conversion of 1phenylethanol and selectivity of acetophenone. It can be seen that conversion of 1-phenylethanol increases from $28 \%$ to $49 \%$ when the amount of Py- $\mathrm{PMo}_{11} \mathrm{~V}$ increases from $0.5 \%$ to $1 \%$ mmol. No significant change in the conversion of 1-phenylethanol was observed when the amount of $\mathrm{Py}-\mathrm{PMo}_{11} \mathrm{~V}$ was between $1 \%$ and
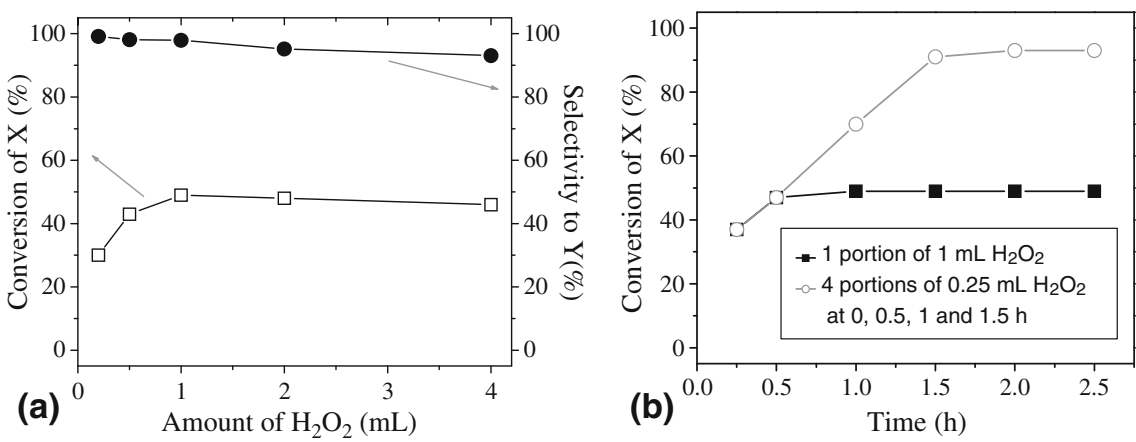

Figure 5. (a) Effect of amount of aqueous hydrogen peroxide $35 \%(\mathrm{w} / \mathrm{v})$ on conversion of 1-phenylethanol (X) and selectivity to acetophenone (Y) using Py$\mathrm{PMo}_{11} \mathrm{~V}$ catalyst; (b) effect of addition of hydrogen peroxide $35 \%(\mathrm{w} / \mathrm{v})$ on conversion of 1-phenylethanol (X) and selectivity to acetophenone (Y) using $\mathrm{Py}_{-} \mathrm{PMo}_{11} \mathrm{~V}$ catalyst. 
$10 \%$ mmol. Selectivity of benzophenone remained constant, 97-98\%. It is independent of the amount of catalyst. Thus, $1 \% \mathrm{mmol}$ of $\mathrm{Py}-\mathrm{PMo}_{11} \mathrm{~V}$ is a suitable amount for this reaction condition.

3.2e Effect of amount of hydrogen peroxide on catalytic oxidation of 1-phenylethanol: Figure 5a shows the influence of the amount of hydrogen peroxide $35 \%$ $(\mathrm{w} / \mathrm{v})$ on conversion of 1-phenylethanol and selectivity of acetophenone using $\mathrm{Py}-\mathrm{PMo}_{11} \mathrm{~V}$. It can be seen that the conversion was dependent on the amount of hydrogen peroxide and reached a maximum value of
$49 \%$ at $1 \mathrm{~mL}$. A slight decrease in the conversion of 1-phenylethanol and in the selectivity of acetophenone was observed with further increase on the amount of hydrogen peroxide. Selectivity decrease may result from further oxidation of acetophenone to 4hydroxyacetophenone.

Results suggest that an excess of hydrogen peroxide is needed for improving substrate conversion although the theoretical molar ratio of hydrogen peroxide to 1phenylethanol for acetophenone production is $1: 1$. This is a consequence of hydrogen peroxide decomposition as reported by Leng and co-workers ${ }^{30}$ for benzene oxidation using a similar catalyst.

Table 2. Oxidation of alcohols to ketones and aldehydes using $\mathrm{Py}-\mathrm{PMo}_{11} \mathrm{~V}$ catalyst.

\begin{tabular}{|c|c|c|c|c|c|}
\hline Entry & Substrate & Product & Time (h) & Conv (\%) & Select $(\%)$ \\
\hline 1 & & & 2 & 93 & 96 \\
\hline 2 & & & 2 & 91 & 99 \\
\hline 3 & & & 2 & 90 & 97 \\
\hline 4 & & & 2 & 93 & 99 \\
\hline 5 & & & 2 & 96 & 98 \\
\hline 6 & & & 2 & 97 & 99 \\
\hline 7 & & & 2 & 93 & 99 \\
\hline 8 & & & 1 & 100 & 81 \\
\hline 9 & & & 1 & 100 & 83 \\
\hline
\end{tabular}

Experimental conditions: $0.01 \mathrm{mmol}$ catalyst, $0.7 \mathrm{mmol}$ of 1-phenylethanol, $1 \mathrm{~mL}$ of $\mathrm{H}_{2} \mathrm{O}_{2} 35 \%(\mathrm{w} / \mathrm{v}), 5 \mathrm{~mL}$ of acetonitrile, $70^{\circ} \mathrm{C}$ 
In order to avoid hydrogen peroxide decomposition, addition of consecutive portions of $35 \%(\mathrm{w} / \mathrm{v})$ hydrogen peroxide was studied. Figure $5 b$ shows the effect of oxidant addition on 1-phenylethanol conversion. Addition of $1 \mathrm{~mL}$ of aqueous hydrogen peroxide at the beginning gives a conversion of 1-phenylethanol of $49 \%$ after $1 \mathrm{~h}$ and remain constant. However, when portions of aqueous hydrogen peroxide are added to the system $(0.25 \mathrm{~mL}$ at $0,0.5,1$ and $1.5 \mathrm{~h}) 1$-phenylethanol conversion increases notably, reaching $93 \%$ at $1.5 \mathrm{~h}$. Acetophenone selectivity was $97 \%$.

3.2f Selective oxidation of alcohols to ketones or aldehydes: Oxidation of other alcohols was then investigated using $\mathrm{Py}-\mathrm{PMo}_{11} \mathrm{~V}$ as catalyst in optimum reaction conditions for 1-phenylethanol $(0.7 \mathrm{mmol}$ of substrate, $1 \mathrm{~mL} 35 \%(\mathrm{w} / \mathrm{v})$ hydrogen peroxide, $1 \%$ mmol of catalyst, $5 \mathrm{~mL}$ of acetonitrile, $70^{\circ} \mathrm{C}$ ). Results are listed in table 2.

High conversion and selectivity were obtained for aromatic secondary alcohol oxidations (table 2, entries 1-7). In the case of aromatic primary alcohols, formation of small amounts of benzoic and 4-chlorobenzoic acid was observed (table 2, entries 8 and 9).

On the other hand, $\mathrm{Py}-\mathrm{PMo}_{11} \mathrm{~V}$ was employed in aliphatic alcohol oxidations, using the above conditions. For secondary alcohols such as 2-octanol and 2-decanol, conversion of $20 \%$ was reached after $2 \mathrm{~h}$. Corresponding ketones were obtained with $95 \%$ of selectivity. Furthermore, a lower conversion was achieved for 1-decanol ( $4 \%$ after $2 \mathrm{~h}$ ); in this case, decanal was obtained with $100 \%$ of selectivity.

\section{Conclusion}

Vanadium and pyridine-modified molybdovanadophosphate catalysts were prepared for selective oxidation of alcohols by aqueous hydrogen peroxide.

Substituted vanadium atoms in heteropolyacids are essentially active sites with high performance for selective oxidation of 1-phenylethanol to acetophenone. Pyridine hybrid catalysts can even promote catalytic activity due to electronic interaction between heteropolyacid and pyridine. $\mathrm{Py}-\mathrm{PMo}_{11} \mathrm{~V}$ exhibits the highest activity for selective oxidation of 1phenylethanol to acetophenone with $93 \%$ of conversion and $96 \%$ of selectivity.

Oxidation of other alcohols was then investigated using $\mathrm{Py}-\mathrm{PMo}_{11} \mathrm{~V}$ catalyst. For benzylic secondary alcohols, conversion and selectivity to the corresponding ketone were very high. No appreciable amounts of by-products were detected. However, for benzylic primary alcohols, selectivity is low due to the formation of carboxylic acids as by-products.

Further investigations on the preparation of new hybrid insoluble heteropolyacids for a more ecofriendly oxidation process (ethanol-water as solvent) are in progress in our laboratory.

\section{Acknowledgements}

The authors thank Graciela Valle for the FTIR measurements and INCA, CONICET, ANPCyT and UNLP for their financial support.

\section{References}

1. Ley S V and Madin A 1991 In: Comprehensive organic synthesis (eds) B M Trost and I Fleming (Oxford: Pergamon) Vol. 7

2. Rahman A, Pullabhotla V S R R and Jonnalagadda S B 2008 Catal. Commun. 92417

3. Lee D G and Spitzer U A 1970 J. Org. Chem. 35 3589

4. Menger F M and Lee C 1981 Tetrahedron Lett. 22 1655

5. Manyar H G, Chaure G S and Kumar A $2006 \mathrm{~J}$. Mol. Catal. A: Chem. 243244

6. Venturello C and Gambero M 1991 J. Org. Chem. 56 5924

7. Zhao W, Zhang Y, Ma B, Ding Y and Qiu W 2010 Catal. Commun. 11527

8. Ma B, Zhang Y, Ding Y and Zhao W 2010 Catal. Commun. 11853

9. Lei Z and Wang R 2008 Catal. Commun. 9740

10. Hosseini-Monfared $\mathrm{H}$, Näther $\mathrm{C}$, Winkler $\mathrm{H}$ and Janiak C 2012 Inorg. Chim. Acta 39175

11. Karthikeyan P, Aswar S A, Muskawar P N, Bhagat P R and Kumar S S 2012 Catal. Commun. 26189

12. Maity P, Gopinath C S, Bhaduri S and Lahiri G K 2009 Green Chem. 11554

13. Zolfigol M A, Khazaei A, Safaiee M, Mokhlesi M, Rostamian R, Bagheri M, Shiri M and Kruger H G 2013 J. Mol. Catal. A: Chem. $\mathbf{3 7 0} 80$

14. Sivaranjani K, Verma A and Gopinath C S 2012 Green Chem. 14461

15. Park D, Park S, Bang Y and Song I 2010 Appl. Catal. A373 201

16. Romanelli G and Autino J 2009 Mini-Rev. Org. Chem. 6359

17. Bennardi D, Romanelli G, Autino J, Pizzio L, Vázquez P, Cáceres C and Blanco M 2010 React. Kinet. Mech. Catal. 100165

18. Romanelli G, Autino J C, Vázquez P, Pizzio L, Blanco M and Cáceres C 2009 Appl. Catal. A352 208

19. Villabrille P, Romanelli G, Quaranta N and Vázquez $P$ 2010 Appl. Catal. B96 379

20. Sambeth J E, Romanelli G, Autino J C, Thomas H J and Baronetti G T 2010 Appl. Catal. A378 114

21. Tundo P, Romanelli G P, Vázquez P G and Aricó F 2010 Catal. Commun. 111181 
22. Tundo P, Romanelli G P, Vázquez P G, Loris A and Aricó F 2008 Synlett 967

23. Villabrille $\mathrm{P}$, Romanelli G, Vázquez $\mathrm{P}$ and Cáceres $\mathrm{C}$ 2008 Appl. Catal. A334 374

24. Romanelli G, Villabrille P, Cáceres C, Vázquez P and Tundo P 2011 Catal. Commun. 12726

25. Rao P S N, Venkateswara Rao K T, Sai Prasad P S and Lingaiah N 2010 Catal. Commun. 11547 (and the references cited herein)

26. Villabrille $\mathrm{P}$, Romanelli $\mathrm{G}$, Vázquez $\mathrm{P}$ and Cáceres $\mathrm{C}$ 2004 Appl. Catal. A270 101

27. Kende A S and Ebetino F H 1984 Tetrahedron Lett. 25 923
28. El Ali B, El-Ghanam A M and Fettouhi M $2001 \mathrm{~J}$. Mol. Catal. A: Chem. 165283

29. Seki Y, Mizuno K and Misono M 2000 Appl. Catal. A194 13

30. Leng Y, Ge H, Zhou C and Wang J 2008 Chem. Eng. J. 145335

31. Cid R and Pecchi G 1985 Appl. Catal. 1415

32. Zhang J, Tang Y, Li G and Hu C 2005 Appl. Catal. A278 251

33. Eguchi K, Seiyama T, Yamazoe N, Katsuki S and Taketa H 1988 J. Catal. 111336

34. Seki Y, Min J S, Misono M and Mizuno N 2000 J. Phys. Chem. B104 5940 